\title{
The economic antecedents of human well being: a pooled mean group estimation of dynamic heterogeneous panel
}

\begin{abstract}
This study seeks to investigate the economic antecedents of happiness by employing the Mean Group (MG), Pooled Mean Group (PMG) and the Dynamic Fixed Effects (DFE) estimators to analyse a set of macro panel data on selected OECD countries for 40 years from 1973 to 2012. The results show evidence that income and unemployment have a favourable impact on happiness, while happiness is hindered by inflation and income inequality. Surprisingly, the study revealed that institutional quality is not a significant antecedent of happiness. It is worth noting the importance of the reference group theory or relative theory of happiness and the set-point theory of happiness in explaining the role played by income, unemployment, inflation, income inequality and institutional quality in explaining human well-being.
\end{abstract}

